\title{
Exceptional association of two species of bacteria causing mediastinitis: Haemophilus influenzae ( $H$. influenzae) and Aggregatibacter aphrophilus (A. aphrophilus)
}

Badia Belarj ${ }^{1 *}$, Souhail Dahraoui ${ }^{1}$, Leila Rar ${ }^{1}$, Noureddine Atmani ${ }^{2}$, Mohammed Frikh', Yassine Ben Lahlou', Adil Maleb ${ }^{3}$, Abdelhay Lemnouer', Mahdi Ait Houssa², Abdelatif Boulahya ${ }^{2}$ and Mostafa Elouennass ${ }^{1}$

\begin{abstract}
Background: Post cardiac surgery mediastinitis is the major infectious complication, despite the development of surgical techniques and the application of strict preventive measures.

The Haemophilus influenzae mediastinitis is very rare. The mediastinitis caused by the association between Haemophilus influenzae and Aggregatibacter aphrophilus has never been described to our knowledge.

Case presentation: We report the case of an exceptional combination of Haemophilus influenzae and Aggregatibacter aphrophilus in a patient operated for single bypass which is complicated by mediastinitis the 10th day after the surgical act.

Conclusion: The conclusion to be drawn from this work is to think in unusual seeds in case of mediastinitis post cardiac surgery for the elaboration of recommendations for antibiotic prophylaxis.
\end{abstract}

Keywords: Post cardiac surgery Mediastinitis, Exceptional association, Haemophilus influenzae, Aggregatibacter aphrophilus

\section{Background}

The postoperative mediastinitis is one of the major infectious complications of cardiac surgery, despite using modern surgical techniques, implementing recommendations regarding antibiotic prophylaxis and conducting a careful skin preparation of the patient.

The incidence of this disease varies between 0.15 to $8 \%[1]$.

Staphylococcus aureus is the species most frequently isolated in post cardiac surgery, Haemophilus influenzae mediastinitis cases are exceptional in addition to the association with Aggregatibacter aphrophilus [2].

We report a case of an exceptional combination between $\mathrm{HI}$ and $\mathrm{AA}$ in a patient with mediastinitis following a single bypass.

\footnotetext{
* Correspondence: flash.moon@hotmail.fr

${ }^{1}$ Hôpital Militaire d'instruction Mohammed V / Université Mohamed V Rabat, Faculté de médecine et de pharmacie de Rabat / Equipe de recherche ERB/ Laboratoire de Bactériologie, Rabat, Morocco

Full list of author information is available at the end of the article
}

\section{Case presentation}

A 74-year old man, hypertensive, diabetic for 30 years, with chronic smoking symptoms, was admitted to the cardiovascular surgery department of the Mohamed $\mathrm{V}^{\text {th }}$ military teaching Hospital of Rabat, for single bypass. Ten days after surgery, the patient had febrile peaks at $39{ }^{\circ} \mathrm{C}$ and purulent sternum discharge. Aerobic and anaerobic blood cultures were performed. The C-reactive protein was at $327 \mathrm{mg}$ per liter and the leukocyte counts to $24^{*} 10^{3}$ cells per microliter, predominantly neutrophils (92\%). In immediate postoperative, the patient developed bronchitis with interstitial pictures on chest radiograph but without purulent secretions.

The scanner has objectified the presence of a hypodense mass in the anterior mediastinum.

Microbiological examination of deep pus drained during a revision surgery of surgical site showed the presence of two bacterial strains (Fig. 1). The identification of bacterial colonies obtained on Chocolate-isovitalex agar, was on

(c) The Author(s). 2018 Open Access This article is distributed under the terms of the Creative Commons Attribution 4.0 International License (http://creativecommons.org/licenses/by/4.0/), which permits unrestricted use, distribution, and 


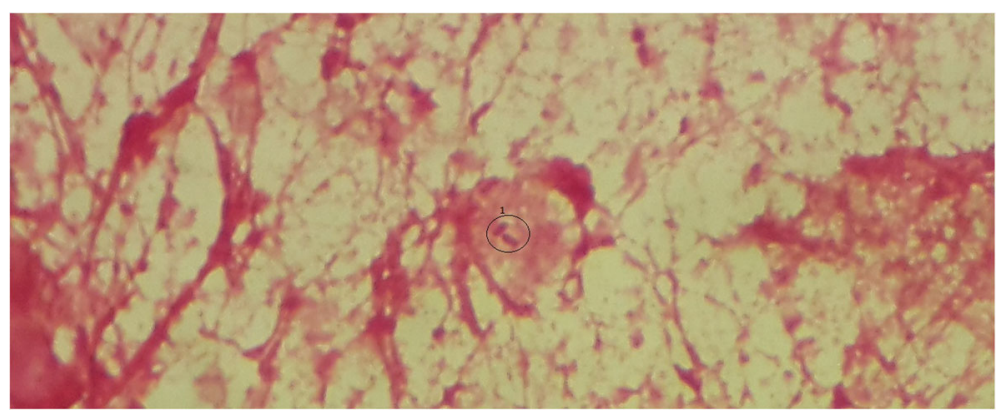

Fig. 1 Microscopic picture (Lens * 100) of the pathological sample showing the presence of Gram-negative bacilli; 1:Gram-negative bacilli

biochemical basis using NH API* strips and bacterial grow in presence of the X-factor and the $\mathrm{V}$-factor on MullerHinton agar which allowed the isolation of Haemophilus influenzae and Aggregatibacter aphrophilus. Susceptibility analysis of the isolated strains was carried out with the disc diffusion methodology according to the CA-SFM". It showed the same susceptibility profile for the 2 strains with a susceptibility to the aminopenicillins, cephalosporins third generation, tetracyclines, quinolones and fluoroquinolones, rifampicin and erythromycin, chloramphenicol and imipenem.

The minimum inhibitory concentration (MICs) of aminopenicillins obtained by E-test strip was $0.75 \mu \mathrm{g} / \mathrm{ml}$ and imipenem was $2 \mu \mathrm{g} / \mathrm{ml}$ (Fig. 2).

Blood culture performed during the same episode objectified the presence of the same bacterial strains with the same susceptibility profile to antibiotics.

The patient was treated by empirical antibiotic therapy: ciprofloxacin (800 $\mathrm{mg}$ per day), cephalosporins third generation ( $2 \mathrm{~g}$ per day) and vancomycin ( $2 \mathrm{~g}$ per day). Treatment was adjusted to the result of susceptibility studies (Amoxicillin $2 \mathrm{~g}$ per day with fluoroquinolone for 3 weeks) with the installation of an irrigation-suction system using suction drains (VAC ${ }^{ø}$ therapy).
The evolution marked by the improvement of the patient on the clinical and biological way after 10 days of curative antibiotic therapy.

\section{Discussion}

Postoperative mediastinitis is a deep infection of the sternum which extends beyond the subcutaneous layer. This is one of the most feared complications in cardiac surgery.

Despite improved means of therapeutic treatment, morbidity and mortality remains high with a mortality rate ranging from 11 to $20 \%[3,4]$.

The contamination of the surgical site is often derived from the commensal flora of the human body (patient or health care team) [5].

The most frequently identified organisms are Staphylococcus aureus (40-60\%) followed by Gram-negative bacilli (BGN) (19\% Enterobacteriaceae (Escherichia coli, Proteus species, Klebsiella pneumoniae) and 5 to $10 \%$ Pseudomonas aeruginosa) and anaerobes. Polymicrobial mediastinitis involving staphylococci, BGN can be seen in $4-30 \%$ of cases. Haemophilus influenzae mediastinitis cases are rare. The association between Haemophilus influenzae and Aggregatibacter aphrophilus in mediastinitis is exceptional $[1,2,6]$.

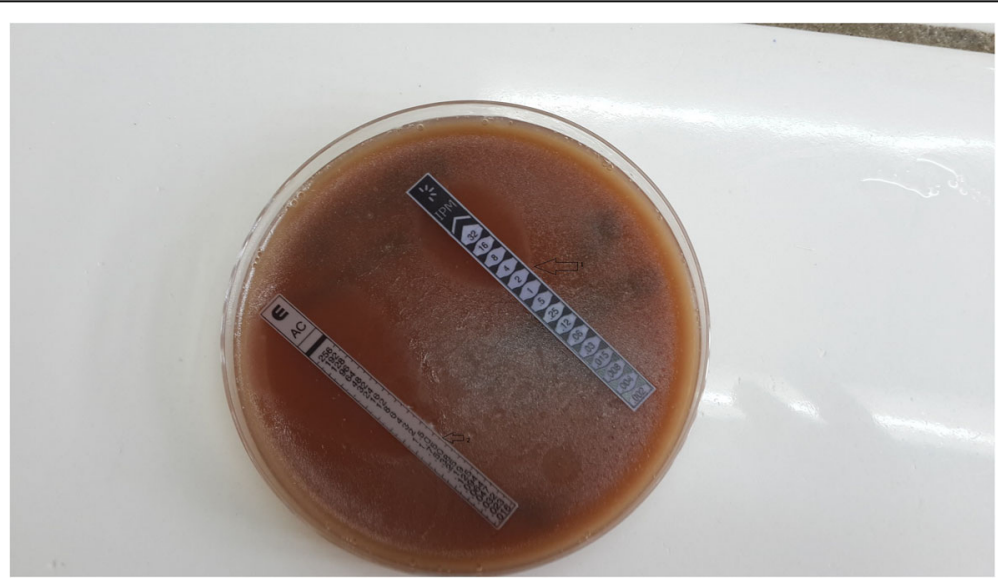

Fig. 2 Photographic image of the MIC made by E-test on chocolate agar; 1: MIC imipenem at $2 \mu \mathrm{g} / \mathrm{ml}$, 2: MIC aminopenicillins at $0.75 \mu \mathrm{g} / \mathrm{ml}$ 
In a wide range of mediastinitis in a 8-years study carried out in France (Charbonneau et al.) 3 cases of Haemophilus influenzae were found; that being a percentage of $0.9 \%$ [7].

In ower knowledge, no associations of Haemophilus influenzae with Aggregatibacter aphrophilus was found.

Haemophilus is a fastidious and polymorphic Gramnegative Coccobacilli, which usually causes a mild infection on many levels, but may also be responsible for serious infections if it reaches parts of the body where it is unusual to find it.

H.aphrophilus, also part of Haemophilus species, was recently transferred (2006) in a new genus: Aggregatibacter [8].

Commensal of the oral cavity and upper respiratory tract in children and adults, the two bacteria have been involved in various infections: endocarditis, brain abscess, meningitis, osteomyelitis and arthritis. Mediastinitis remains however a very rare location [9].

The identification of these microorganisms is based on biochemical properties but molecular biology remains more efficient (RNA $16 \mathrm{~s}$ or sequencing) [8].

Factors contributing to the development of post-surgical mediastinitis are multiple and dependent on the type of surgery: covers of sternotomy; postoperative bleeding and those dependent on patient history including chronic obstructive pulmonary disease, smoking, diabetes and obesity $[1,2,5,6,8,10]$.

In our case, the patient was smoker and diabetic and, he showed an immediate postoperative bronchitis which would likely cause the bacteremia in these two germs.

A study in Nantes on post cardiac surgery mediastinitis, shows the association of this clinical entity with pneumonia in $77 \%$ of cases, responsible for a prolongation of mechanical ventilation and, therefore an extension of stay in intensive care. This raises the question of whether the infection was transmitted to the lung by bacterial translocation or bacteremia or conversely if mediastinitis could be secondary to pneumonia [6].

Treatment of mediastinitis includes: the treatment of septic shock and associated visceral failures, antibiotic therapy and aspiration guided by ultrasound or surgical exploration with drainage $[2,5,11]$.

As recommended empiric antibiotic therapy should include vancomycin or a cephalosporin, associated with an aminoglycoside or a fluoroquinolone with adjustment to the results of susceptibility testing for a period of 3 weeks [1].

The beta-lactams are top choice antibiotics for treating infections with H.influenzae both in adults and in children. However, there are many mechanisms of resistance, the most common being the production of beta-lactamase. It is primarily TEM-type enzyme. A decreased susceptibility to beta-lactams by modification of the penicillin binding proteins (PBPs) target this antibiotic family is another mechanism which can add an efflux mechanism $[7,8,10,12,13]$.

The in vitro activity of various antibiotics tested showed that cefotaxime and cefpodoxime have better activity in terms of MIC 50 and MIC interval, followed by amoxicillin + clavulanic acid that restores the activity of amoxicillin over the stem producing only betalactamase. Cefuroxime and cefaclor are less active in vitro regardless of the phenotype of the strains tested. Similar results have been reported in Europe and North America [7, 8, 10, 12, 13]. The Poor dissemination of beta-lactams and glycopeptides bone level often leads to associate with other molecules, such as fluoroquinolones, rifampin or fucidin [14].

For our patient, antibiotic therapy was at first probabilistic based on vancomycin associated with fluoroquinolone then was switched to aminopenicillin following the result of MICs with fluoroquinolone for a period of 3 weeks.

\section{Conclusion}

The Haemophilus influenzae mediastinitis are very rare while the association with A.aphrophilus is exceptional whose inoculation mechanism remains undocumented in our case.

Knowing that H.influenzae culture requires the presence of $\mathrm{V}$ and $\mathrm{X}$ factors that are present in fresh blood, it is likely that the bleeding occurred postoperatively in our patient was a favorable condition for the growth and multiplication of the germ.

\section{Abbreviations \\ A. aphrophilus: Aggregatibacter aphrophilus; BGN: Gram-negative bacilli; CA-SFM*: Antibiogram committee of the French Society for Microbiology; H. influenzae: Haemophilus influenzae; MIC: Minimum inhibitory concentration;

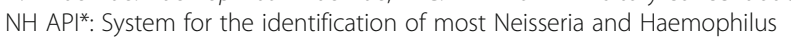 spp.; PBPs: Penicillin binding proteins; RNA 16 s: Ribo nucleic acid $16 \mathrm{~s}$}

\section{Acknowledgements}

We thank all the team of the bacteriology laboratory HMIMV for technical assistance.

\section{Availability of data and materials}

All data analysed during this case are included in this published article.

\section{Authors' contributions}

BB: conception and study design, acquisition of data, analysis and interpretation, drafting of the manuscript. DS: substantial contributions to conception and participated in the drafting of the paper. RL, FM, BY, MA: participated in acquisition of data and bibliographic research. LA: Interpretation of data, revision of the manuscript draft. AN, AM, BA: has been involved in revising critically the paper for important intellectual content. EM: has been involved in conception and design of the paper and has given final approval of the version to be published and agreed to be accountable for all aspects of the work in ensuring that questions related to the accuracy or integrity of any part of the work are appropriately investigated and resolved. All authors read and approved the final paper.

Ethics approval and consent to participate Not applicable 


\section{Consent for publication}

We did obtain written consent for publication of this case report.

\section{Competing interests}

The authors declare that they have no competing interests.

\section{Publisher's Note}

Springer Nature remains neutral with regard to jurisdictional claims in published maps and institutional affiliations.

\section{Author details}

${ }^{1}$ Hôpital Militaire d'instruction Mohammed V / Université Mohamed V Rabat, Faculté de médecine et de pharmacie de Rabat / Equipe de recherche ERB/ Laboratoire de Bactériologie, Rabat, Morocco. ${ }^{2}$ Hôpital Militaire d'instruction Mohammed V / Université Mohamed V Rabat, Faculté de médecine et de pharmacie de Rabat / Service de chirurgie cardiovasculaire, Rabat, Morocco. ${ }^{3}$ Centre Hospitalo-Universitaire Mohammed VI Oujda, Université Mohammed Premier Oujda, Faculté de médecine et de pharmacie Oujda / Laboratoire de Bactériologie, Oujda, Morocco.

Received: 5 April 2017 Accepted: 24 July 2018

Published online: 16 August 2018

\section{References}

1. Nguyen D-C, Nguyen H-T. Postoperative mediastinitis: diagnosis and treatment. EMC-Cardiologie Angéiologie. 2005;2:337-43.

2. Lepelletier D, Perron S, Michaud JL. Médiastinites après chirurgie cardiaque : incidence, microbiologie et facteurs de risque. Pathologie infectieuse; Antibiotiques. 2005;7:18-22.

3. Maleb A, Nya F, Amahzoune B, Lemnouer A, Elouennass M. Postoperative mediastinitis due to Candida tropicalis: first reported case in Morocco. J Mycol Méd. 2014;24(3):225-8.

4. Costache V, Gaudreau G, Houde C, Rodière M, Hacini R, Blin D, Chavanon O. Intérêt de l'association VAC ${ }^{\oplus}$-thérapie, ostéosynthèse sternale et lambeaux pectoraux d'avancement dans la prise en charge d'une médiastinite postopératoire après chirurgie cardiaque chez une obèse diabétique. Ann Chir Plast Esthét. 2010;55(6):597-602.

5. Bourigaul LC, Roussel JC, Lasserre C, Leclère B, Corveca S, Pattierb S, Lepoivre T, Baron O, Despins P. Epidemiology and prevention of surgical site infections after cardiac surgery. Med Mal Infect. 2013;43(10):403-9.

6. Lepelletier D, Poupelin L, Corveca S, Bourigault C, Bizouarn P, Blanloeil Y, Reynaud A, Duveau D, Despins P. Risk factors for mortality in patients with mediastinitis after cardiac surgery evaluation. Arch Cardiovasc Dis. 2009;102: 119-25.

7. Charbonneau H, et al. Mediastinitis due to Gram-negative bacteria is associated with increased mortality. Clin Microbiol Infect. 2014;20:0197-202.

8. Nørskov-Lauritsen N. Classification, identification, and clinical significance of Haemophilus and Aggregatibacter species with host specificity for humans. Clin Microbiol Rev. 2014;27(2):214-40.

9. David Martin A, Reema H, Dbouk B, Marlene Deleon-Carnes C, del Rio C, Guarner J. Haemophilus influenzae acute endometritis with bacteremia: case report and literature review. Diagn Microbiol Infect Dis. 2013;76(2):235-6.

10. Rehman SM, et al. Risk factors for mediastinitis following cardiac surgery: the importance of managing obesity. J Hosp Infect. 2014;88:96-102.

11. Durrleman N, El Hamamsy I, Hébert Y, Pellerin M, Carrier M, Perrault LP. Modalités thérapeutique des médiastinites en chirurgie cardiaque. Chir Thor Cardio-Vasc. 2006;10:4-17.

12. Darras-Joly C, et al. Haemophilus endocarditis: report of 42 casesin adult and review. Clin Infect Dis. 1997;24:1087-94.

13. Dabernata $H$, Seguya M, Fauconb G, Delmasa C. Épidémiologie et évaluation de la sensibilité aux antibiotiques de souches d'Haemophilus influenzae isolées en 2004 en France. Med Mal Infect. 2007; 37(6):320-32.

14. Lecharny JB, Tapia M, Baudot J, Philip I. Médiastinites après chirurgie cardiaque. Conférences d'actualisation; 2001. p. 677-92.

\section{Ready to submit your research? Choose BMC and benefit from}

- fast, convenient online submission

- thorough peer review by experienced researchers in your field

- rapid publication on acceptance

- support for research data, including large and complex data types

- gold Open Access which fosters wider collaboration and increased citations

- maximum visibility for your research: over $100 \mathrm{M}$ website views per year

At BMC, research is always in progress.

Learn more biomedcentral.com/submissions 